\title{
Tras la imagen del coleccionista: influencia y protagonismo de Manuel Castellano en el desarrollo y la conservación del retrato fotográfico en Madrid
}

\author{
Behind the collector: influence and protagonism of Manuel \\ Castellano on the photographic portrait's development \\ and conservation in Madrid
}

Stéphany ONFRAY
Universidad Complutense de Madrid

Recibido: 24-X-2015

Aceptado: 28-III-2016

Resumen: La completa definición del papel de Manuel Castellano en la formación y la conservación de sus 24 álbumes fotográficos, sigue siendo hoy en día materia de discusión. En este artículo, pretendemos esbozar la figura del pintor como un elemento clave, no sólo para la recopilación del conjunto de fotografías, sino para el propio desarrollo del retrato fotográfico en los estudios madrileños en el siglo XIX.

Palabras clave: Colección Castellano, Fotografía, Siglo XIX, Manuel Castellano, Carte de visite.

ABSTRACT: It is true that the actual definition of the role of Manuel Castellano in the formation and conservation of his photographic collection remains unknown. In this paper, we claim that this Spanish painter was a key element for the conservation of this impressive heritage, but also for the development of the photographic portrait in Madrid, in the nineteenth century.

Keywords: Castellano Collection, Photography, 19th century, Manuel Castellano, Carte de visite.

\section{INTRODUCCIÓN}

Si comparamos la amplitud de la Colección Castellano -unas 18.000 piezas fotográficas ${ }^{1}$ - con los pocos estudios que le han

\footnotetext{
${ }^{1}$ En este artículo nos centraremos en los retratos en
} estudio, unas 17.000 piezas, divididas en 22 álbumes. sido dedicados, quizá resulte ser una de las colecciones menos estudiadas y aprovechadas de España. La información en torno a sus condiciones de formación y a su creador resulta todavía más escasa, aunque poco a poco van apareciendo nuevas teorías y planteamientos. La falta de documentación y la 


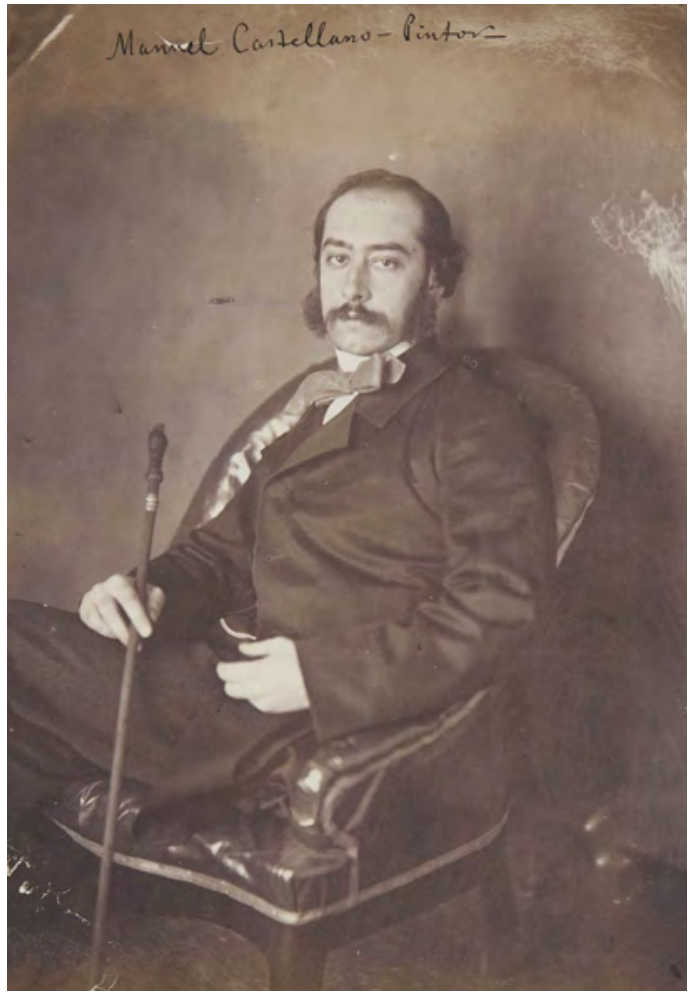

- Fig. 1. Retrato de Manuel Castellano. Biblioteca Nacional de España. Fotografías recogidas por el pintor Manuel Castellano. Tomo 14, 17LF/59-033. 1.

profusión numérica del fondo complican su entendimiento global y, sobre todo, impiden determinar las razones que empujaron a Manuel Castellano (1826-1880) (Fig. 1) a reunir y conservar estos 22 álbumes de retratos entre 1850 y 1872.

\section{MANUEL CASTELLANO, PINTOR Y COLECCIONISTA}

Disponemos de muy poca información en torno a la vida personal y artística de Manuel Castellano. La única faceta de su producción que ha sido realmente estudiada es su obra pictórica. Además de pintor fue dibujante, poeta, empresario y coleccionista.Nacido en 1826 en Madrid, murió en 1880 en la misma ciudad ${ }^{2}$. Denominado por todos como "pintor de historia" ${ }^{3}$, estudió

\footnotetext{
${ }^{2}$ M. OSSORIO Y BERNARD, Galería biográfica de artistas españoles del siglo XIX, Madrid, 1883-1884, p.147.

${ }^{3}$ E. BLASCO, "Manuel Castellano", Día de Moda, año $\mathrm{I}, \mathrm{n}^{\circ} 9,5$ de abril de 1880 , p.4.
}

la pintura bajo la dirección de Juan Ribera ${ }^{4}$ en la Real Academia de Bellas Artes de San Fernando, y fue ayudante ${ }^{5}$ de su hijo Carlos Ribera $^{6}$. Aunque nunca se posicionó realmente dentro del panorama de los pintores más famosos de la época, tuvo una carrera galardonada con numerosos premios ${ }^{7}$; e incluso disfrutó en los últimos años de su vida de una pensión en la Academia española en Roma $^{8}$. Desafortunadamente se conservan pocas de sus obras al óleo, pero gracias a su constante labor de recopilación y conservación de su propia producción, se han podido atesorar numerosos esbozos de sus encargos o de los figurines que producía para sus amigos dramaturgos. Asimismo, era un hombre "de sociedad", extremamente popular en el ámbito cultural del Madrid decimonónico, interesado desde fecha muy temprana por la práctica de coleccionar objetos artísticos.

El debate en torno al carácter coleccionista de Manuel Castellano resulta ser una cuestión central a la hora de definir las condiciones de formación de la colección. No existen dudas en cuanto a considerarlo o no como un coleccionista, ya que él mismo identificaba los numerosos objetos recopilados como: "perteneciente a la Colección del Pintor Manuel Castellano" ${ }^{\prime 9}$ (Fig. 2). El punto

${ }^{4}$ M. OSSORIO Y BERNARD, Op. cit., p.146.

${ }^{5}$ Los dos pintores Juan Antonio de Ribera (17791860) y su hijo Carlos Luis de Ribera (1815-1891) aparecen retratados en varias ocasiones en la Colección Castellano. Véase para Juan Antonio de Ribera: Biblioteca Nacional de España (en adelante BNE), Fotografías recogidas por el pintor Manuel Castellano, Tomo 13, 17-LF/589, Retrato de Juan Antonio de Ribera e Ibídem, 17-LF/58-11, Retrato de Juan Antonio de Ribera. Para Carlos Luis de Ribera: Ibídem, Tomo 19, 17-LF/42-9, Retrato de Carlos Luis de Ribera e Ibídem, 17-LF/42-10, Retrato de Carlos Luis de Ribera.

${ }^{6}$ VV.AA., Artistas pintados. Retratos de pintores y escultores del siglo XIX en el Museo del Prado. Catálogo de la exposición, Madrid, 1997, pp. 108-109.

$$
\begin{aligned}
& { }^{7} \text { M. OSSORIO Y BERNARD, Op. cit., pp.146-147. } \\
& { }^{8} \text { Ibídem, p.147. }
\end{aligned}
$$

${ }^{9}$ Es por ejemplo el caso de la carta escrita por José Martínez Sánchez: BNE, MSS/12946/35, Carta de José Martínez Sánchez a Manuel Castellano, s.f. Carta citada en 


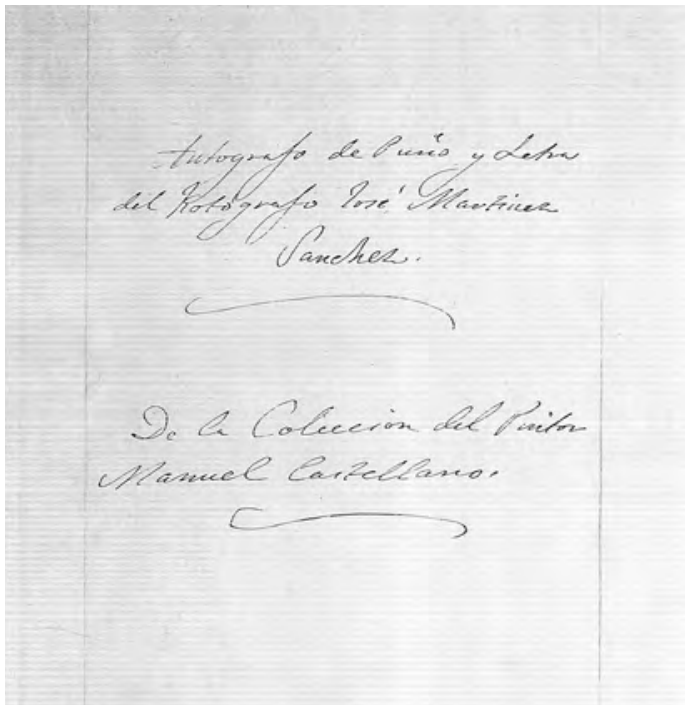

- Fig. 2. Reproducción de la anotación de Manuel Castellano en la Carta de José Martínez Sánchez a Manuel Castellano. Biblioteca Nacional de España. s.fol. MSS/12946/35.

clave sería delimitar si dispuso o no de una colección de 22 tomos de retratos. Desde su entrega en la Biblioteca Nacional en $1872^{10}$, el conjunto de álbumes siempre fue considerado como perteneciente al pintor, ya que él mismo había entregado una gran parte del mismo $^{11}$. Es solamente a partir del año 1989 cuando hicieron su aparición teorías que ponían en duda su pasión de coleccionista, o su papel activo en la formación de los tomos. En este sentido, Publio López Mondéjar apuntaba que las fotografías sólo serían un medio pictórico de la época, utilizadas por Castellano para realizar sus cuadros, y prestadas a su círculo artístico para que si-

D. SÁNCHEZ CANO, «El coleccionismo de fotografía en España y la colección Castellano», BSAA Arte, no 74, 2008, p. 265.

${ }^{10} \mathrm{~J}$. E. HARTZENBUSCH, Memoria leída en la Biblioteca Nacional en la sesión pública del presente año 1872, Madrid, 1872, p. 9, publicado en J. M. SÁNCHEZ VIGIL (coord.), Summa Artis XLVII. La fotografía en España, de los orígenes al siglo XXI, Madrid, 2001, p.188 (Nota 19).

${ }^{11}$ La segunda parte de la colección fue entregada a su muerte por su hermano. BNE, BNE-A, BN 0016/048, Relación de estampas y dibujos comprados por la Biblioteca Nacional a Ramón Rodríguez Castellano, 5 de julio de 1880. A este propósito me gustaría agradecer la inmensa ayuda de Isabel Ortega, Belén Palacios, Amparo Beguer y Enrique Pérez, así como de todo el personal de la BNE.

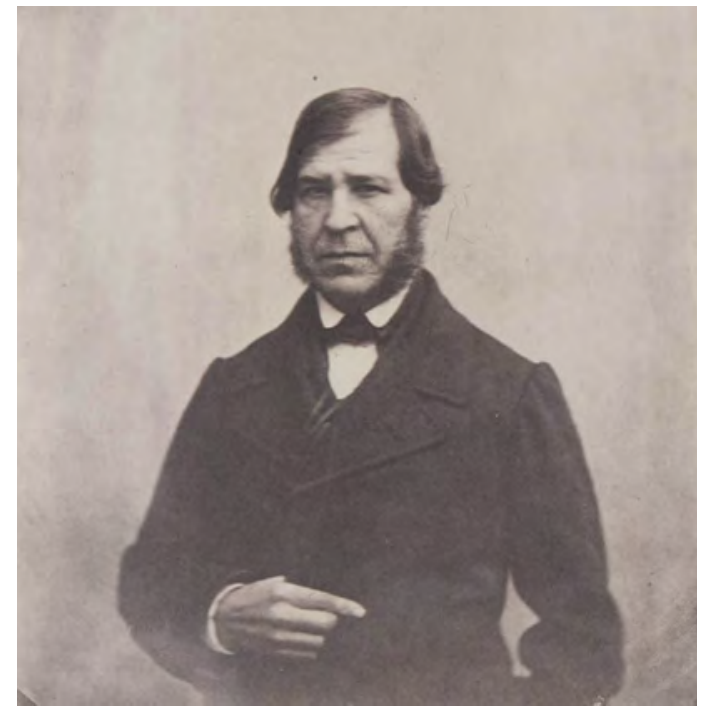

- Fig. 3. Retrato de José Martínez Sánchez. Biblioteca Nacional de España. Fotografías recogidas por el pintor Manuel Castellano. Tomo 10, 17LF/55-093.1.

guieran su modelo. Según el historiador, esta falta de consideración artística hacia la fotografía, evidenciada por la ausencia de firma por parte de los fotógrafos, vendría a corroborar la idea "baudeleriana" según la cual la fotografía sería una "simple auxiliar o criada de las otras artes"12. Esta hipótesis no resulta improbable, ya que numerosos artistas empleaban material fotográfico para sus esbozos. Sin embargo, vemos como poco posible que se trate de la única intención de Manuel Castellano a la hora de conservar 18.000 positivos. Otra teoría sería la de Gerardo Kurtz, que afirma que muchas de las fotografías eran de la mano de José Martínez Sánchez (1807-1874), fotógrafo especialmente activo en la década de 1860 en Madrid (Fig. 3). Incluso, se barajó la opción que algunos álbumes fueran las muestras utilizadas en la sala de espera de su estudio. Esta hipótesis fue recogida y completada por María José Rodríguez Molina y José Ramón Sanchís Alfonso en 2014. Estos últimos alegan que Manuel Castellano fue en realidad un simple intermediario entre la Biblioteca Nacional y el estudio de José Martínez Sánchez. Para ellos, la colección solamente pasó

${ }_{12}$ P. LÓPEZ MONDEJAR, Historia de la fotografía en España, Barcelona, 2003, p. 56. 
por las manos del pintor entre 1869 y 1871, cuando el fotógrafo decidió volver a su ciudad natal, Valencia ${ }^{13}$. Obviamente, es muy difícil negar la importancia de la autoría de José Martínez Sánchez en la formación de esta colección. Basta comparar formalmente los suelos y objetos decorativos visibles en carte de visite firmadas por José Martínez Sánchez ${ }^{14}$, con las fotografías de los tomos. Por tanto, es posible afirmar que muchas fotografías habrían sido sacadas por él.

Aun así, consideramos algo prematuro el hecho de restar cualquier responsabilidad en la formación de la colección a Manuel Castellano. En este sentido, nuestra opinión se acerca más a la de Joan Fontcuberta, emitida en el apéndice "Notas sobre la fotografía española", de la reedición de 1983 de Historia de la Fotografía de Beaumont Newhall ${ }^{15}$. Fontcuberta sí destaca el papel coleccionista del pintor, y explica que reunía expresamente una galería de retratos para enseñarla a su círculo social, como era entonces muy usual. Al considerar esta hipótesis a la luz de la amplia correspondencia de Manuel Castellano, encontramos una carta escrita por Luis de Montes que así lo afirma: "Mi querido amigo Manuel; no olvido su promesa de usted de hacerme ver su rica colección de fotografía. Cuando usted disponga, y a la hora que se sirva señalarme tendría el gusto de ir a su casa» ${ }^{16}$. Castellano disponía pues de una colección fotográfica propia que enseñaba a sus conocidos.

${ }^{13}$ M. J. RODRÍGUEZ MOLINA y J. R. SANCHÍS ALFONSO, Una nueva visión de la fotografía española: La obra de José Martínez Sánchez (1807-1874), Valencia, 2014, p. 100.

${ }^{14}$ Estas muestras están disponibles en otras colecciones madrileñas, como es el caso de la Fundación Lázaro Galdiano. J. M. SÁNCHEZ VIGIL y M. OLIVERA ZALDUA (coords.), Una Imagen para la Memoria. La carte de visite. Colección de Pedro Antonio de Alarcón, Madrid, 2011, pp. 134-135. Aprovechamos para agradecer a Juan Antonio Yeves Andrés por su paciencia y atención.

${ }^{15}$ J. FONTCUBERTA, "Apéndice: Notas sobre la fotografía española", en B. NEWHALL, Historia de la fotografía, Barcelona, 1983, p.305.

${ }^{16} \mathrm{BNE}, \mathrm{MSS} / 12946 / 21$, Carta de Luis de Montes a Manuel Castellano, 8 de abril s.a.
Es más, esta muestra era motivo de tertulia con personalidades artísticas de su entorno, como es el caso de Luis de Montes, entre otros muchos. Desgraciadamente, la ausencia de fecha concreta para esta carta no nos permite afirmar de manera segura que dicha colección estaba en manos del pintor antes de 1869. Sin embargo, el hecho de que este documento se encuentre conservado entre un lote de cartas de Luis de Montes, fechadas entre 1856 y 1860, fortalece esta posibilidad. Una segunda correspondencia entre Mariano Bort y Virués y el pintor, sí podría ser una prueba de la existencia de una colección de fotografía perteneciente a Castellano ya en la década de los 1860. En una primera carta, fechada el 10 de septiembre de 1864, Bort evoca un "cajón" que le gustaría mandar al pintor: "Querido Manolo: Supongo la buena fama que estaré ganando para contigo, por no haberte remitido las fotografías en el tiempo que te manifesté, pero he experimentado unas contrariedades para no poder cumplir con mi deseo"17. Otra carta confirma la recepción de dicho cajón lleno de fotografías, el 15 de octubre de $1864^{18}$, con lo cual sabemos que Castellano disponía por lo menos de un conjunto de fotografías sueltas después de este año.

El argumento principal para afirmar la estrecha relación que tenía el pintor con el coleccionismo fotográfico nos lo proporciona un intercambio entre éste último, y Luis Mariano de Larra (1830-1901) (Fig. 4). De esta manera, Larra escribía a Castellano el 11 de abril de 1861: "Lo prometido es deuda, necesito una tarjeta tuya y otra de Adela: si no tienes el grupo de Fernando ${ }^{19}$ yo te lo daré en cambio ${ }^{20}$. Un año antes, Castellano recibía una petición de parte de su amigo: "Querido Manolo: el [dador] va (sic) por dos o tres ál-

${ }^{17}$ BNE, MSS/12937/82, Carta de Mariano Bort y Virués a Manuel Castellano, 10 de septiembre de 1864.

\footnotetext{
${ }^{18}$ Ibídem, 15 de octubre de 1864.

${ }^{19}$ Podría tratarse de Fernando Castro, personaje que aparece a menudo en la Colección Castellano.
}

${ }^{20}$ BNE, MSS/12938/81, Carta de Luis Mariano de Larra a Manuel Castellano, 11 de abril de 1861. 


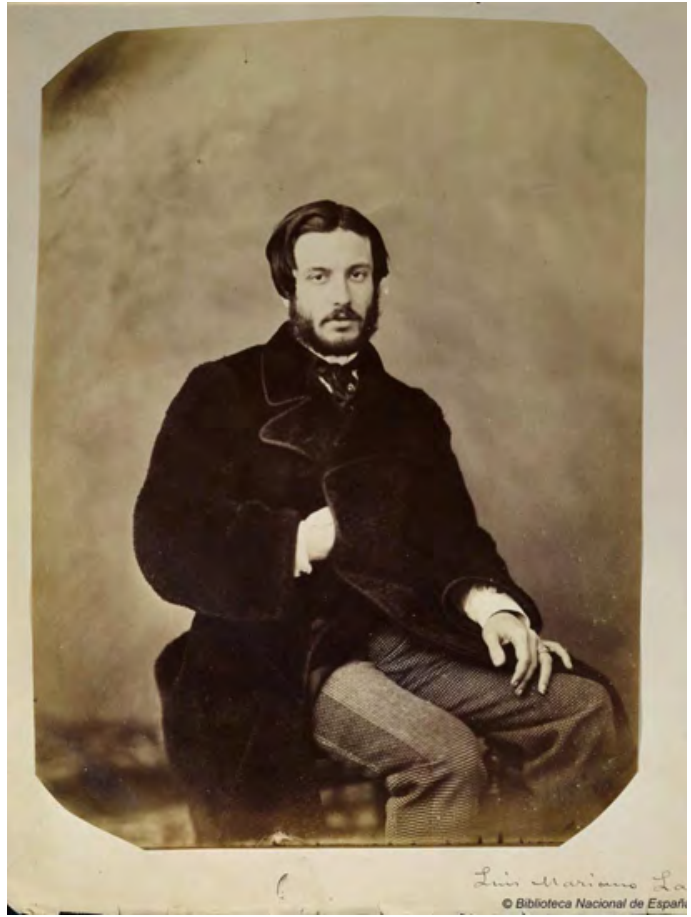

- Fig. 4. Retrato de Luis Mariano de Larra. Biblioteca Nacional de España. Fotografías recogidas por el pintor Manuel Castellano. Tomo 18, 17LF/63-009.

bumes para que [...] los vea mi señora. Dale si quieres los que yo vi porque son personas conocidas y le gustará más. Cuando los termine te los remandaré y me darás otros"21. Estos documentos no sólo confirman el desarrollo de un intercambio de fotografías entre los dos hombres, sino que la colección fotográfica de Manuel Castellano -siendo la de la Biblioteca Nacional de España o no- ya estaba dividida y conservada en álbumes. De hecho, la carta de Larra parece insinuar que los álbumes eran relativamente numerosos, tanto que atraían la curiosidad ajena como es el caso de la mujer de este último, o del citado Luis de Montes.

\section{LA FORMACIÓN DE LA COLECCIÓN CASTELLANO}

Afirmar que Manuel Castellano era efectivamente coleccionista de fotografía no significa por tanto que haya formado él mismo los tomos conservados en la Biblioteca Nacional. No obstante, al seguir analizando la corres-

\footnotetext{
${ }^{21}$ Ibídem, 18 de febrero de 1860.
}

pondencia de Castellano, pudimos ver que numerosas personas identificadas en el conjunto de fotografías pertenecían a su ámbito más íntimo. Castellano era entonces un hombre muy sociable, que se movía en los círculos del arte y del teatro de la época. Era amigo de los mejores dramaturgos, pintores o actores. En este sentido, también se conserva correspondencia con varios fotógrafos madrileños de la época, o por lo menos cartas atestiguando su relación -y su probable cooperación- con ellos. Es por ejemplo el caso de Jean Laurent ${ }^{22}$, o bien de Eusebio Juliá, al que Manuel Castellano ayudaba en la tasación de unos cuadros en la década de $1870^{23}$. Pero lo más interesante sería la carta del propio fotógrafo José Martínez Sánchez, ya que confirma una colaboración entre los dos hombres: "Amigo Castellanos (sic). Necesitaría ver a usted para hablar de unos dibujos de toros que quiere un sugeto (sic) para reproducirlos en fotografía" 24 . Dentro del panorama fotográfico madrileño también existen vínculos entre el pintor y otras personalidades, como José María Sánchez (fotógrafo activo entre 1850 y 1870) (Fig. 5). Podría existir una relación laboral entre los dos hombres, ya que se hallan imágenes de ambos donde se percibe una fuerte $\operatorname{amistad}^{25}$ (Fig. 6). Es más, estas fo-

${ }^{22}$ BNE, MSS/12940/42, Carta de Jean Laurent a Manuel Castellano, 12 de enero de 1872. Carta citada en D. SÁNCHEZ CANO, Op. cit., p.265.

${ }^{23}$ BNE, MSS/12940/85, Carta de Eusebio Juliá a Manuel Castellano, Carta citada en D. SÁNCHEZ CANO, Op.c.it., 18 de noviembre de 1870. “Querido Manolito. La casa donde te has de tomar la molestia de ver los cuadros de que te hablé es la del Procurador de Faure, Calle de Mesón de Paredes nำ15, 1ํㅜ portal, diciendo vas a mi nombre y por conducto de D. Manuel de Diego. Ya sabes mi objeto por lo cual te abstendrás de decir allí tu parecer en cuanto al precio [...], tu buen amigo Eusebio Juliá". Es importante precisar que Eusebio Juliá era un familiar de Carlos Ribera, maestro de Manuel Castellano.

${ }^{24}$ Podemos considerar esta carta anterior a la vuelta de José Martínez Sánchez a Valencia, entre 1869 y 1870. Véase M. J. RODRÍGUEZ MOLINA y J. R. SANCHÍS ALFONSO, Op. cit., p.10.

${ }^{25}$ La serie de tres fotografías de estos dos hombres posando en grupo y solos nos permite sugerir esta relación amistosa: BNE, Fotografías recogidas por el pintor Manuel Castellano, Tomo 14, 17-LF/55-100, Retrato de José Sánchez, Alejandre, José Laserna, y Manuel Castella- 


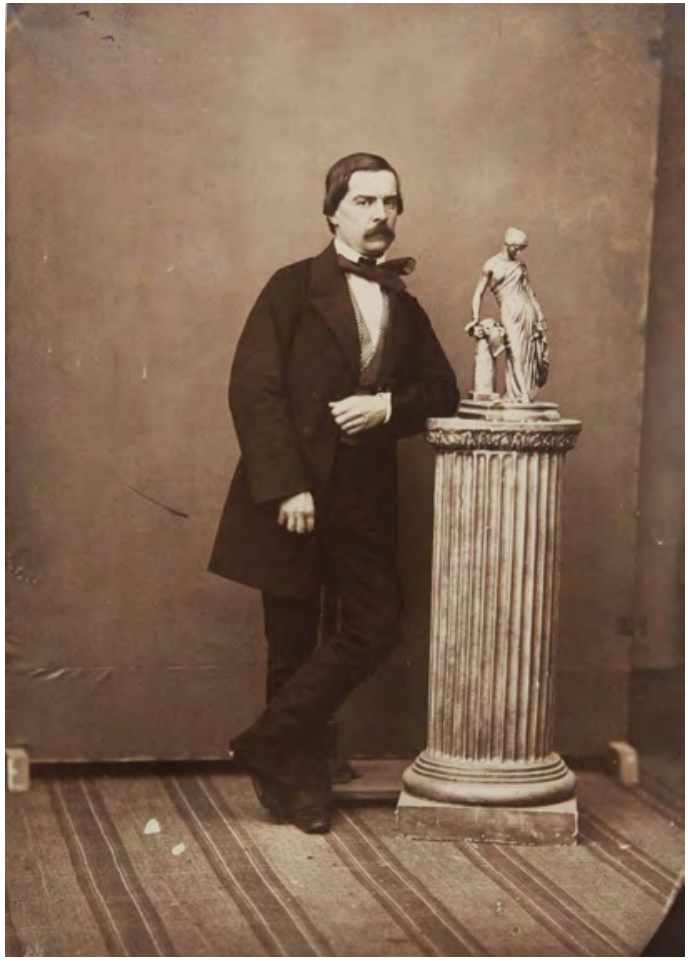

- Fig. 5. Retrato de José María Sánchez. Biblioteca Nacional de España. Fotografías recogidas por el pintor Manuel Castellano. Tomo 14, 17LF/59-101.

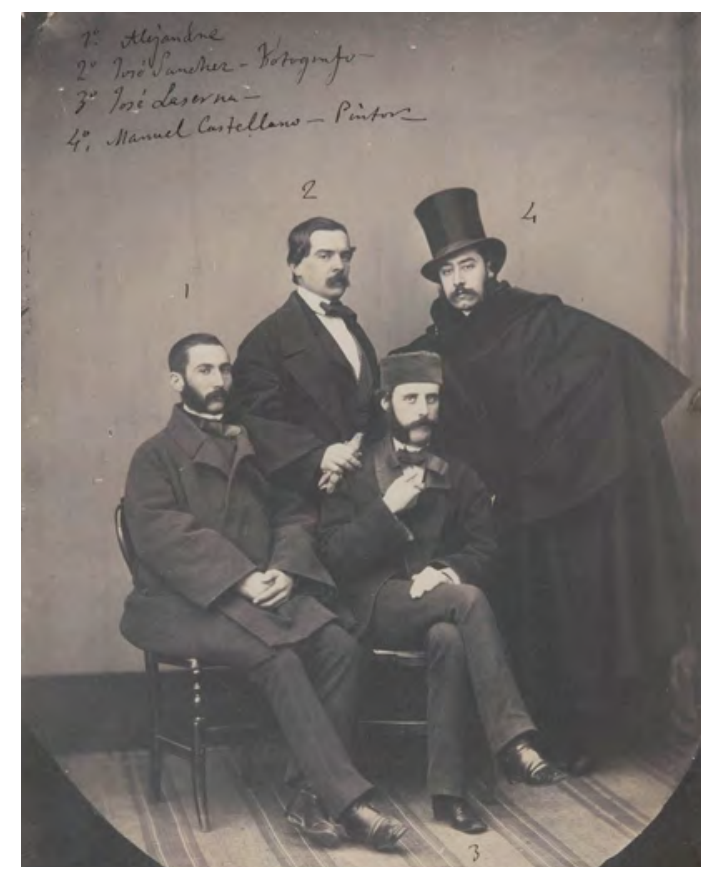

- Fig. 6. Retrato de Alejandre, José María Sánchez, José Leserna y Manuel Castellano. Biblioteca Nacional de España. Fotografías recogidas por el pintor Manuel Castellano. Tomo 14, 17-LF/59100. tografías podrían provenir del propio estudio de José María Sánchez ${ }^{26}$. Asimismo, los hermanos de ambos hombres estaban implicados en diversos juegos fotográficos. Encontramos a José Castellano posando en el mismo estudio en curiosas puestas en escena, o incluso a Manuel Castellano de espaldas, junto con el hermano de José María Sánchez y el fotógrafo Juan $\mathrm{Mon}^{27}$. Este dato resulta aún más interesante si consideramos que José Sánchez seguramente fue ayudante de José Martínez Sánchez ${ }^{28}$, e insinúa un posible vínculo entre los tres hombres. Así pues, el pintor tenía una relación cercana con varios de los más importantes fotógrafos madrileños, cuyas piezas llenan los tomos de la colección. Sin embargo, la correlación entre los personajes retratados y las cartas conservadas en la Biblioteca Nacional no se limita a los fotógrafos. Más de un tercio de los remitentes de esta correspondencia figuran una o varias veces en los tomos. Pensamos concretamente en los ya citados Mariano Bort y Luis Montes, pero también en Adelaida Fernández de Zapatero (Fig. 7) con la que Castellano parece haber tenido una relación en la década de 1860, y con la que se retrató en numerosas ocasiones ${ }^{29}$.

no, 1857; Ibídem, 17-LF/55-101, Retrato de José Sánchez, 1857 e Ibídem, 17-LF/55-102, Retrato de Manuel Castellano, 1857.

${ }^{26}$ La comparación del suelo de las fotografías citadas en la nota precedente y de una fotografía de Manuel Castellano posando en esta misma alfombra -firmada por José María Sánchez en 1859- hallada en otra colección de la BNE, nos permite deducir que José Sánchez sería el autor de esta fotografía. Incluso es probable que se trate de algunas de las alfombras que empleaba en su estudio. Véase BNE, Iconografía Hispana, IH-1909-3, Retrato de Manuel Castellano por José María Sánchez, 1859. Esta afirmación nos permite por lo tanto identificar la autoría de muchas otras fotografías.

${ }^{27} \mathrm{BNE}$, Fotografías recogidas por el pintor Manuel Castellano, Tomo 10, 17-LF/55-46, Retrato de Manuel Castellano, junto con el hermano de José María Sánchez, y el fotógrafo Juan Mon.

${ }^{28}$ M. J. RODRÍGUEZ MOLINA, y J. R. SANCHÍS ALFONSO, Op. cit., p.22.

29 D. SÁNCHEZ CANO, Op. cit., p. 268. Oficialmente Manuel Castellano vivió toda su vida en Madrid y murió soltero. Sin embargo, existen varias cartas de 


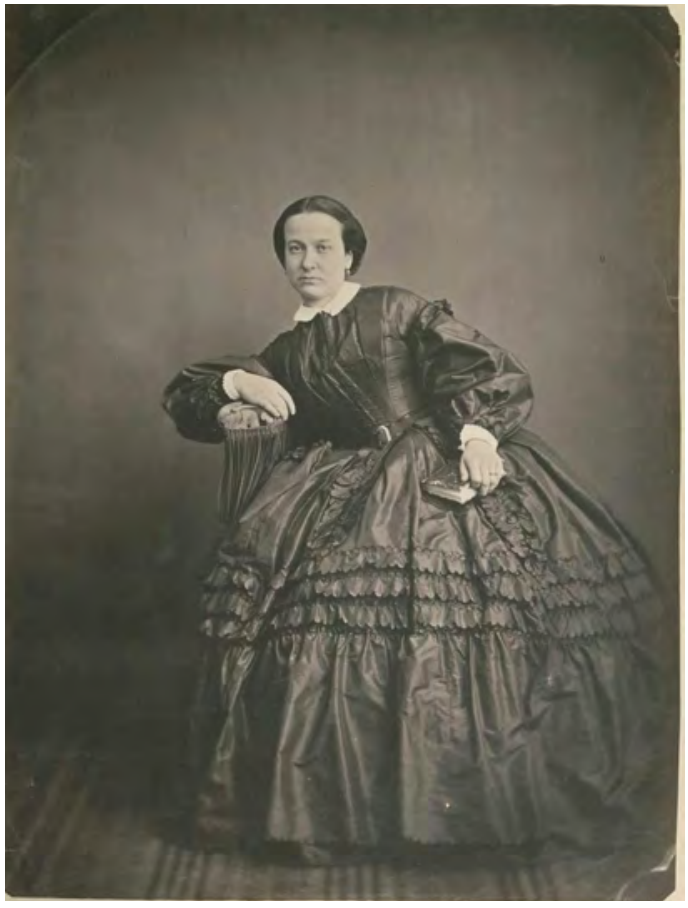

- Fig. 7. Retrato de Adelaida Fernández de Zapatero. Biblioteca Nacional de España. Fotografías recogidas por el pintor Manuel Castellano. Tomo 18, 17-LF/63-053.

Con el propósito de certificar la actividad de Manuel Castellano en la formación de la colección se ha tratado de establecer una correspondencia entre la letra del pintor y las anotaciones presentes en el anverso de las fotografías. Estas son primordiales, ya que aportan en muchos casos información sobre la identidad de los retratados, su actividad y, en algunos casos, hasta la fecha

Manuel Catalina donde el actor saluda con afección a una cierta "Adela": BNE, MSS/12940/85, Carta de Manuel Catalina a Manuel Castellano, 15 de enero de 1861 y 8 de mayo de 1861. Imaginamos que se podría tratar de Adelaida Zapatero Fernández (actriz activa en Madrid entre los años 1860 y 1890). Para ello, nos basamos en varias fotografías en las que los dos posan juntos: BNE, Fotografías recogidas por el pintor Manuel Castellano, Tomo 11, 17-LF/56-165.3, Retrato de Adela Fernández de Zapatero y Manuel Castellano; Ibídem, 17-LF/56-175.3, Retrato de Adela Fernández de Zapatero y Manuel Castellano. También resulta significativo el hecho de que parte de la correspondencia personal de la actriz se encuentra actualmente conservada entre la colección del pintor. Entre esta correspondencia hallamos una carta de Adelaida Zapatero muy personal, dirigida a su "Querido Lolo". Véase BNE, MSS/12940/111, Carta de Adelaida Fernández de Zapatero a un amigo, s. fol. del retrato. Para ello, las comparamos con su libro manuscrito de poesías El Oso del Par$n a \mathrm{So}^{30}$, igualmente conservado en los fondos de la Biblioteca Nacional. Para evitar sacar conclusiones apresuradas, hemos decidido ceñirnos a la confrontación de palabras enteras y no de caracteres únicos. Nos basamos entonces en numerosos nombres, de los que resaltaremos el del pintor Francisco Reigón, que aparece tanto en las poesías ${ }^{31}$, como escrito en sus respectivas fotografías (Fig. 8) ${ }^{32}$.

Una vez analizada la correspondencia de las escrituras pudimos evidenciar que muchas anotaciones podrían ser de la mano de Manuel Castellano. De este modo, estamos en posición de afirmar que aunque el pintor hubiera comprado los álbumes a José Martínez Sánchez, también quiso participar en su elaboración identificando a los personajes representados. $\mathrm{El}$ acceso a todas las anotaciones del reverso de las fotografías ${ }^{33}$, y su comparación con la letra de Castellano, podrían aportar datos fundamentales para saber si se encargó él mismo de pegar las fotografías en los tomos ${ }^{34}$. Gracias a la consulta de álbumes, en los que un número escaso de fotografías se encuentran ligeramente despegadas, sabemos que existen anotaciones detrás de las fotografías y que algunas de ellas pueden ser atribuidas -a nuestro juicio- a la mano de Manuel Castellano. Es por ejemplo el caso de una imagen denominada La muger

${ }^{30}$ BNE, MSS/2709, El Oso del Parnaso. Colección de poesías de Manuel Castellano [manuscrito], ca.18501880.

${ }^{31}$ Ibídem, p.34.

${ }^{2}$ También podríamos citar los nombres de Juan Antonio Ribera si comparamos El Oso del Parnaso (Ibídem, p. 32) con la inscripción, presente en la Colección Castellano: BNE, Fotografías recogidas por el pintor $\mathrm{Ma}$ nuel Castellano, Tomo 14, 17-LF/59-98-2, Retrato de Juan Antonio Ribera (fotografía despegada).

${ }^{33}$ Queremos agradecer la ayuda de Isabel Ortega, que nos permitió acceder a una base de datos con transcripción de una parte de estas anotaciones.

${ }^{34}$ En efecto, semejante análisis aseguraría que el pintor pegó él mismo las imágenes en las páginas, después de haberlas comentado en sus anversos y reversos. 

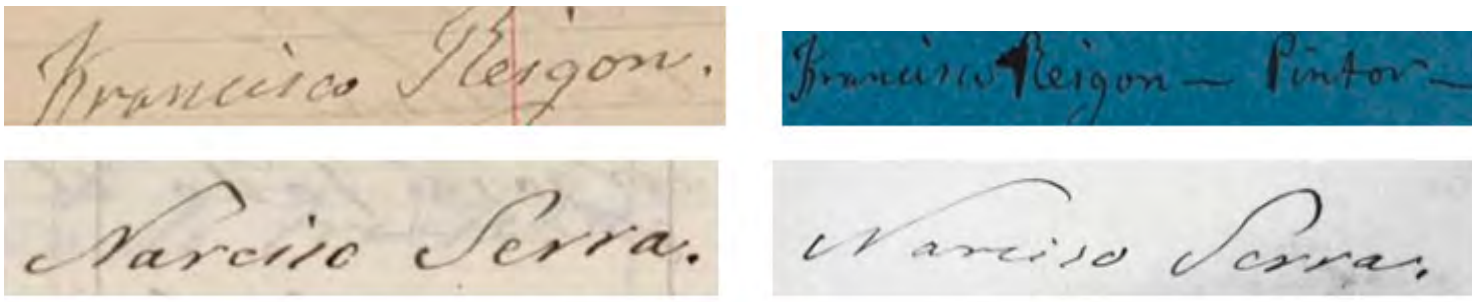

- Figs. 8 y 9. Comparación entre las grafías de los álbumes de la Colección Castellano y el libro de poesía del pintor Manuel Castellano. El Oso del Parnaso. Biblioteca Nacional de España.

del Infante Don Sebastián, de 1861, conservada en el tomo 6 de la colección ${ }^{35}$. Al comparar la letra de las anotaciones del anverso de la fotografía, y centrándonos en particular en la palabra "muger" (sic), comprobamos que la letra se corresponde con la misma palabra escrita en El Oso de Parnaso ${ }^{36}$. Sin embargo, el ejemplo más flagrante sigue siendo el de una fotografía suelta, conservada en la colección de Iconografía Hispana de la BNE. Pudimos observar la correspondencia de la letra de Castellano con la anotación del reverso de la fotografía de Narciso Serra ${ }^{37}$-poeta amigo de Castellano pero sobre todo de Adelaida Fernández (Fig. 9). Por ello afirmamos que los álbumes de la Colección Castellano no pueden ser -por lo menos en su totalidadatribuidos a José Martínez Sánchez ${ }^{38}$, sino que Manuel Castellano identificó muchas de las fotografías, además de pegarlas en los tomos. De este modo se refuerza la idea se-

${ }^{35}$ BNE, Fotografías recogidas por el pintor Manuel Castellano, Tomo 6, 17-LF/51-056.5, Retrato de la muger del Infante Don Sebastián, de 1861.

${ }^{36}$ BNE, MSS/2709, El Oso del Parnaso. Colección de poesías de Manuel Castellano [manuscrito], ca.1850-1880, p.4.

37 BNE, Iconografía Hispana, IH-8839-1, Retrato de Narciso Serra. La letra de estas anotaciones también corresponde con la grafía de una carta perteneciente a la correspondencia de Zapatero, en las que Castellano había escrito: "Carta escrita de puño y letra por la Actriz Adelaida Fernández de Zapatero a Narciso Serra". Véase BNE, MSS/12940/112, Carta de Adelaida Zapatero a Narciso Serra, 25 de diciembre s.a.

38 También se ha defendido la hipótesis según la cual José Martínez Sánchez no apuntaba él mismo las anotaciones en los álbumes, sino que se encargaban sus ayudantes. Véase M. J. RODRÍGUEZ MOLINA y J. R. SANCHÍS ALFONSO, Op. cit., pp.129-130. gún la cual el pintor tuvo efectivamente una importante labor compositiva en la gestión y creación de la colección.

\section{MANUEL CASTELLANO Y LA FO- TOGRAFÍA}

Otra cuestión fundamental sería el determinar las razones que le empujaron a reunir semejante fondo fotográfico, cuando el nuevo medio no disponía precisamente de una gran popularidad en el mundo artístico. Al aparecer la carte de visite, la fotografía se transformó en una atracción popular, sin embargo lejos aún de implantarse en el ámbito artístico. A lo largo de este estudio sobre la relación de Castellano con la fotografía, hemos podido descubrir que lo que le interesaba en realidad, no sólo era la colección de retratos, sino la reunión de objetos artísticos de todo tipo. El pintor poseía numerosos muestras decorativas o arqueológicas ${ }^{39}$, pero también disponía de una biblioteca muy amplia. Sabemos que concedía numerosos préstamos a sus amigos y que a veces ellos le devolvían el favor incrementando su biblioteca con algún ejemplar ${ }^{40}$. También conservaba con especial cuidado cada carta que recibía, no sólo por su uso personal, sino por las propias firmas que compilaba ${ }^{41}$. Como ya

${ }^{39}$ En una carta dirigida a José Amador de los Ríos (también coleccionista de retratos fotográficos) Manuel Castellano ofrece al Museo Arqueológico un capitel de piedra que cree del siglo XIV, comprado en Toledo. BNE, MSS/12938/56, Carta de Manuel Castellano a José Amador de los Ríos, 21 de abril de 1868.

${ }^{40}$ BNE, MSS/12946/21, Carta de Luis de Montes a Manuel Castellano, 1856-1860.

${ }^{41}$ De hecho, en cada una de las cartas Manuel Castellano indicaba que se trataba de una "firma de puño y 
se ha podido comprobar, algunas de estas cartas presentan un interés muy particular para comprender cómo se formaron sus diferentes colecciones. Sus amigos tenían una gran preocupación por ayudarle a satisfacer esta predilección y hemos localizado en su correspondencia varias pruebas que lo certifican. Se dirigen al "hombre de las cosas curiosas" ${ }^{42}$, "tan curioso y guardador de libros" ${ }^{43}$, y quieren "aumentar la colección de curiosidades" $44 \mathrm{o}$ "enriquecer su preciosa colección" ${ }^{\prime 4}$. También le enviaban libros ${ }^{46}$, hojas árabes recogidas en Tetuán ${ }^{47}$, rollos de retratos y poemas cubanos ${ }^{48}$, autógrafos ${ }^{49} \mathrm{O}$ "papeletas" 50 .

El hecho de que Manuel Castellano posicionara la fotografía en el mismo plano que la mayoría de los objetos de su colección dice mucho del valor artístico que otorgaba al nuevo medio, algo bastante inusual en esta época. Tampoco sorprende el acercamiento de Manuel Castellano a los estudios fotográficos, si consideramos la fuerte relación que unió la fotografía con el mundo del espectá-

letra", perteneciendo a la "Colección del Pintor Manuel Castellano". Es importante resaltar que todas las cartas encontradas no estaban destinadas al pintor, sino que disponía también de la correspondencia de sus amigos. Aparecen por ejemplo notas de Adela Zapatero, de Manuel Catalina, etc.

${ }^{42}$ BNE, MSS/12946/21, Carta de Luis de Montes a Manuel Castellano, 18 de mayo de 1860.

${ }^{43}$ BNE, MSS/12937/13, Carta de Francisco Asenjo Barbieri a Manuel Castellano, 6 de marzo de 1874.

${ }^{44}$ BNE, MSS/12945/55, Carta de Pascual de Riesgo a Manuel Castellano, 27 de septiembre de 1874.

${ }^{45}$ BNE, MSS/12947/21, Carta de Enrique Arjona a Manuel Castellano, 22 de junio de 1854.

${ }^{46}$ BNE, MSS/12937/13, Carta de Francisco Asenjo Barbieri a Manuel Castellano, 6 de marzo de 1874.

${ }^{47}$ BNE, MSS/12946/21, Carta de Luis de Montes a Manuel Castellano, 18 de mayo de 1860.

${ }^{48}$ BNE, MSS/12945/55, Carta de Pascual de Riesgo a Manuel Castellano, 27 de septiembre de 1874.

${ }^{49}$ BNE,MSS/12937/13, Carta de Francisco Asenjo Barbieri a Manuel Castellano, 3 de abril de 1871.

${ }^{50}$ BNE, MSS/12947/21, Carta de Enrique Arjona a Manuel Castellano, 22 de junio de 1854. culo en el siglo XIX. Desde muy temprano, el pintor mantuvo una estrecha relación con el teatro, del que formó gran parte de su círculo social; mantenía amistades con los actores Manuel y Juan Catalina, el compositor Francisco Barbieri o el dramaturgo Juan Eugenio Hartzenbusch, así como con varias actrices ${ }^{51}$. Colaboraba con muchos de ellos en asuntos teatrales. Era por ejemplo encargado -entre otras cuestiones- de las cuentas del Teatro del Príncipe mientras Juan Catalina era director $^{52}$, y ayudaba a Francisco Barbieri en la producción de figurines para el Teatro de la Zarzuela ${ }^{53}$. La propia necrológica del pintor -escrita por Eusebio Blasco- sólo puede confirmar esta fuerte afición del "pintor-actor" 54 : «Todo el que haya pasado una vez de telón a dentro en los teatros de verso, habrá conocido a Manuel Castellano. Era un pintor notable, que además tenía la pasión del teatro. Íntimo de Manuel Catalina, ha sido durante muchos años el consejero áulico de su teatro. Para él no había más mundo que el de los bastidores. Se sabía de memoria todas nuestras comedias, antiguas y modernas; era un almacén de títulos, de versos, de biografías. Asistía á todas las lecturas, llevaba la cuenta de los ingresos, daba su opinión sobre las obras, enseñaba á los actores los modelos de sus trajes de época, y era al mismo tiempo que un hombre francote, decidor, espontáneo" ${ }^{\prime \prime 5}$. Estas palabras se refuerzan gracias a la correspondencia de Castellano, en la que comprobamos como diferentes personalidades del mundo del espectáculo

\footnotetext{
${ }^{51} \mathrm{Su}$ correspondencia habla, por ejemplo, de una amistad muy fuerte con Matilde Diez, actriz madrileña que aparece a menudo en la Colección Castellano. Nos referimos en particular a una carta de año nuevo en la que la actriz dice: "Sabe usted que se le quiere mucho, $\mathrm{y}$ aunque amigos de poco tiempo no por eso el cariño es menos verdadero y leal". BNE, MSS/12939/52, Carta de Matilde Diez a Manuel Castellano, 6 de enero de 1861.

${ }^{52}$ E. BLASCO, Op. cit., p.3.

${ }^{53}$ Podemos en particular citar los figurines de Pan y Toros. Véase BNE, MSS/12937/13, Carta de Francisco Asenjo Barbieri a Manuel Castellano, 1864.

${ }^{54}$ E. BLASCO, Op. cit., p.4.

${ }^{55}$ Ibídem.
} 
se dirigen a él para diferentes cuestiones. Eso incluye tanto el obtener el parecer del pintor sobre su última creación teatral ${ }^{56}$, reservar alguna butaca para la sesión del día ${ }^{57}$, o incluso realizar encargos de figurines ${ }^{58}$. Estos elementos permiten esbozar el camino que Manuel Castellano siguió hasta llegar a los estudios fotográficos, y no extrañaría que el pintor se posicionase como eje central entre estos mismos y algunos teatros madrileños.

Como bien señaló Roland Barthes, "No es (me parece) a través de la Pintura como la Fotografía entronca con el arte, es a través del Teatro" ${ }^{\prime 2}$. La interrelación entre las dos artes se fue dibujando muy temprano en la historia del nuevo medio. De hecho, su utilización por parte del mundo del espectáculo fue una de las mayores vías de difusión de la fotografía, y en particular gracias a la carte de visite ${ }^{60}$. Mediante estas imágenes, el público pudo recordar más fácilmente a sus artistas favoritos, surgiendo así una suerte de ancestro del star-system hollywoodense. Muy rápidamente los retratos de actores se transformaron en una faceta muy productiva del trabajo del fotógrafo, lo que podemos comprobar al ver que muchos de ellos se instalaron en calles cercanas a los grandes teatros de la época. Es por ejemplo lo que hizo Eusebio Juliá en 1864, al mudarse a dos pasos del Teatro del Príncipe -actual

${ }^{56}$ BNE, MSS/12946/130, Carta de Mariano Carreras y González (Escritor y profesor de economía) a Manuel Castellano, 1869

57 Entre numerosas otras cartas podemos citar a BNE, MSS/12944/7, Carta de Antonio Olivares a Manuel Castellano, 1870

${ }^{58}$ BNE, MSS/12939/2, Carta de Francisco Barbieri a Manuel Castellano, 1870.

${ }^{59}$ R. BARTHES, La cámara lúcida, Barcelona, 2006, p.64.

${ }^{60}$ Antes de 1854 la tarjeta de visita estaba hecha con un pequeño trozo de papel donde quedaban descritos los datos de presentación de un hombre. La inclusión de una fotografía acentuó el carácter divulgativo del objeto y lo expandió a muchos sectores profesionales, de los que sobresale el de los artistas del espectáculo. Estos retratos se vendían en las propias casas de fotógrafos, y los más solicitados en las librerías especializadas.
Teatro Español- donde Manuel Castellano se encargaba precisamente de las entradas. Es fácil imaginar que su estudio se transformó en un lugar de encuentro para el mundo del espectáculo. Además como ya sabemos gracias a las cartas del pintor, ambos se conocían más estrechamente ${ }^{61}, \mathrm{y}$ varios amigos suyos se hicieron retratar en el estudio ${ }^{62}$. Los dos hombres adquirieron tanta complicidad que Eusebio Juliá permitió al pintor publicar sus poesías en el Almanaque de su estudio, cuando hasta la fecha el pintor sólo las había enseñado a algunos íntimos ${ }^{63}$. Sin embargo, en los dos Almanaques conservados en la Biblioteca Nacional no aparece el nombre de Castellano en la lista de ilustres retratados del estudio de Juliá. La posibilidad de consultar algún Almanaque anterior permitiría probablemente afirmar que Castellano y Juliá no sólo se conocían, sino que el fotógrafo había retratado al pintor.

No resulta descabellado imaginar que algunos de los numerosos retratos de Manuel Castellano presentes en la colección hubieran sido realizados por el fotógrafo ${ }^{64}$. Cada uno de estos retratos son muestras de la particular atracción del pintor hacia el juego con la cámara. De hecho, entre 1853 y 1869 el pintor se hizo retratar más de treinta y seis veces. Gracias a la existencia de este material, tenemos constancia de la evolución física del pintor, pero también indicios de una personalidad cautivada por la inquietud artística, de la que el medio fotográfico fue quizá su mejor aliado. El pintor compartirá esta afición con numerosos amigos pintores,

${ }^{61}$ BNE, MSS/12940/85, Carta de Eusebio Juliá a Manuel Castellano, 18 de noviembre de 1870 .

${ }^{62}$ Es por ejemplo el caso de Juan Catalina. Véase BNE, MSS/12946/85, Carta de Juan Catalina a Manuel Castellano, 8 de mayo de 1861 .

63 BNE, MSS/12944/126, Carta de Francisco Reigón (Pintor) a Manuel Castellano, 9 de abril de 1853.

${ }^{64}$ La correspondencia de los suelos de algunas fotografías de la colección con los de fotografías firmadas por Juliá nos permite afirmarlo. Véase P. LINÉS VIÑUALES, "Posar en un escenario: la imagen en la carte de visite", en J. M. SÁNCHEZ VIGIL y M. OLIVERA ZALDUA (coords.), Op. cit., pp.127-136. 


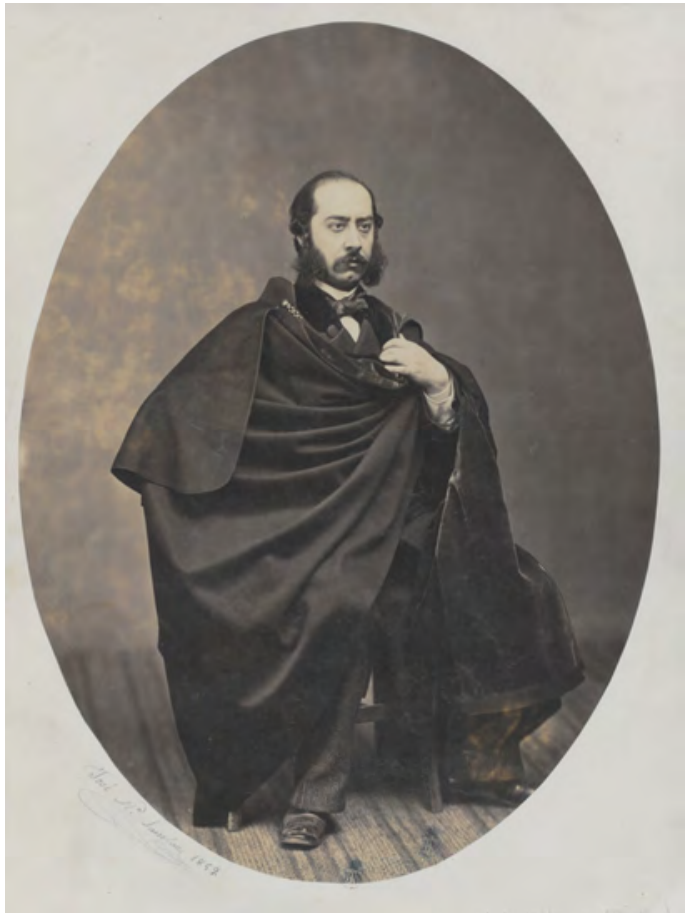

- Fig. 10. Retrato de Manuel Castellano. Biblioteca Nacional de España. Iconografía Hispana. IH1909-3.

fotógrafos o actores como Francisco Reigón, José María Sánchez o Adelaida Fernández de Zapatero. Aunque muchas veces incorpora objetos cotidianos a sus retratos -algo consustancial al gusto de la época- es preferentemente ante un fondo sencillo y completamente solo como el pintor prefiere lucir en numerosas ocasiones ${ }^{65}$. Asimismo, sus retratos reflejan un gusto exquisito por la moda masculina: dispone de decenas de conjuntos diferentes, con accesorios de cierto status como la capa, el sombrero de copa o incluso una fusta ${ }^{66}$ (Fig. 10). Al límite de la performance teatral experimentaba con actuaciones y posados ante la cámara; ello se debe seguramente a la fuerte afinidad que le unía con los fotógrafos que le retra-

\footnotetext{
${ }^{65}$ Encontramos muy pocas fotografías en la que utiliza un fondo pintado: BNE, Fotografías recogidas por el pintor Manuel Castellano, Tomo 9, 17-LF/54-004.1, Retrato de Manuel Castellano, diciembre de 1861. También resulta muy interesante otra fotografía en la que el pintor posa delante de una puerta: Ibídem, Tomo 3, 17-LF/48054.V.3, Retrato de Manuel Castellano, mayo de 1865.

${ }^{66}$ Ibídem, Tomo 16, 17-LF/61-063.2, Retrato de Manuel Castellano, 1858.
}

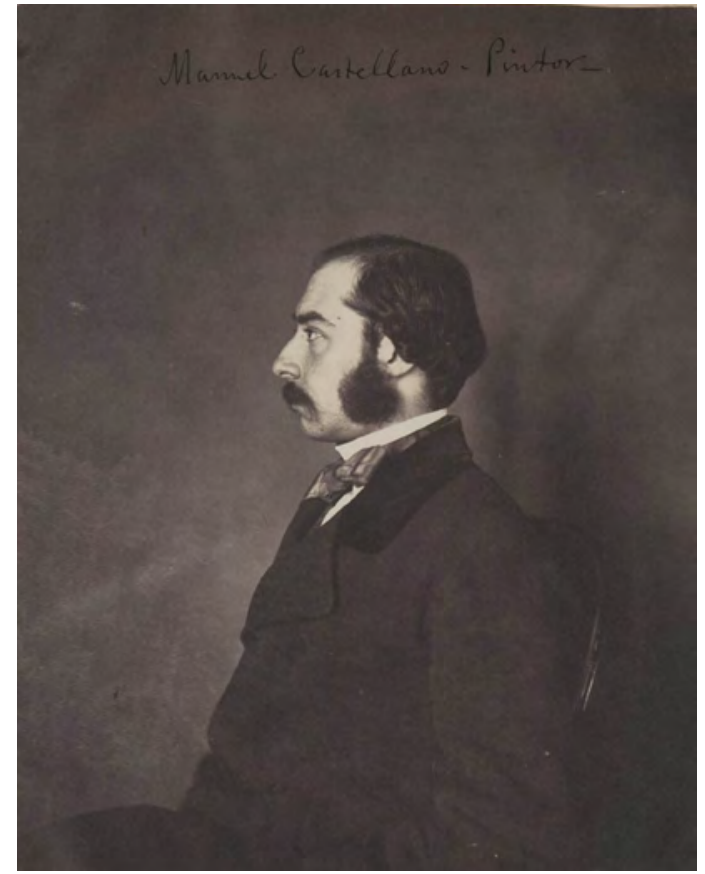

- Fig. 11. Retrato de Manuel Castellano. Biblioteca Nacional de España. Fotografías recogidas por el pintor Manuel Castellano. Tomo 14, 17LF/59-060.1

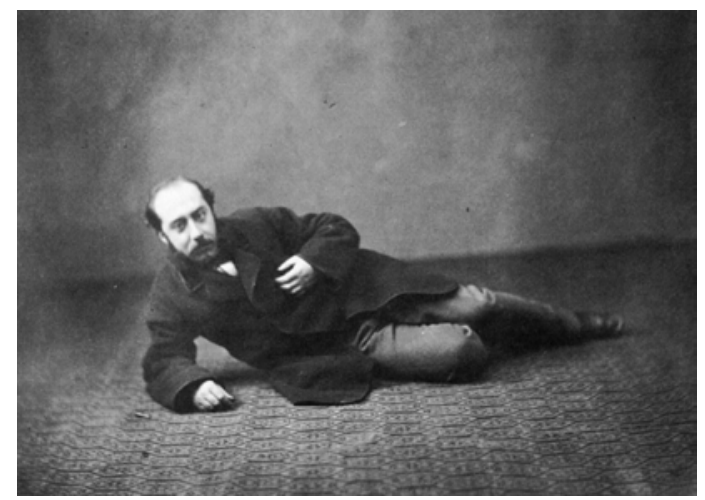

- Fig. 12. Retrato de Manuel Castellano. Biblioteca Nacional de España. Fotografías recogidas por el pintor Manuel Castellano. Tomo 11, 17$\mathrm{LF} / 56-02$.

taban. Es más, aparte de documentar la existencia de un juego social -más que presente en los retratos de la época- estas imágenes muestran el evidente deseo de constante innovación visual. Resulta sorprendente ver como el pintor permitía a los fotógrafos explorar posturas poco empleadas en la época. Castellano posa de perfil $^{67}$ (Fig. 11), de pie,

${ }^{67}$ Ibídem, Tomo 14, 17-LF/59-060.1, Retrato de Manuel Castellano, 1853. 
sentado $^{68}$, y hasta tumbado en la moqueta ${ }^{69}$ (Fig. 12). La idea de un diálogo constante entre el fotógrafo y Manuel Castellano subyace en estas imágenes. De modo que no se puede excluir una cierta colaboración entre el operador y el modelo a la hora de organizar la "puesta en escena". El fotógrafo podía experimentar con ángulos diferentes o aproximar la cámara hacia el pintor, buscando nuevos tipos de representación y lenguaje, lo que no se podía concebir con los clientes normales ${ }^{70}$. Gracias a este conjunto de retratos se desarrolla la idea de un Manuel Castellano amante de la fotografía, que la valoraba como algo más que un medio de propaganda social. Su cercana relación con los fotógrafos y su soltura frente al objetivo desvelan su capacidad para considerarla como un nuevo medio de expresión personal.

\section{LA DONACIÓN DEL FONDO A LA BIBLIOTECA NACIONAL}

Si uno sopesa la fuerte relación que unía a Manuel Castellano con la fotografía podría sorprender la donación de la mayor parte de su colección a la Biblioteca Nacional en 1872. Hemos de suponer que las razones de semejante donativo se centran más bien en la voluntad de un reconocimiento más ambicioso para el fondo. Tampoco hay que excluir el hecho de que, en aquel entonces, el pintor ya se estaba planteando la solicitud de una beca de residencia en la Academia española en Roma. En cualquier caso, no deja de ser la alta consideración artística que otorgaba a sus fotografías la que le hizo plantearse -con la influencia de su amigo Juan Eugenio de Hartzenbusch ${ }^{71}$ la inclusión de parte del voluminoso fondo

${ }^{68}$ Ibídem, Tomo 14, 17-LF/59-102, Retrato de Manuel Castellano, 1857.

${ }^{69}$ Ibídem, Tomo 11, 17-LF/56-082, Retrato de Manuel Castellano, noviembre de 1859.

${ }^{70}$ Ibídem, Tomo 14, 17-LF/59-033.1, Retrato de Manuel Castellano, 1856.

71 Es interesante añadir que Juan Eugenio de Hartzenbusch aparece varias veces en la Colección Castellano: Ibídem, Tomo 18, 17-LF/41-007.1, Retrato Juan Eugenio de Hartzenbusch; Ibídem, Tomo 1,17-LF/46-012, en la institución. En este sentido, en 2001 se publica un esbozo fundamentado de las circunstancias de la llegada de la colección a la Biblioteca Nacional ${ }^{72}$. Se trata de una Memoria leída en la Biblioteca Nacional en la sesión pública del presente año 1872, en la que Juan Eugenio Hartzenbusch (1806-1880) -entonces director de la Biblioteca Nacional ${ }^{73}$ y también coleccionista de fotografías ${ }^{74}$ - anuncia: "Hemos cedido una porción considerable de estampas duplicadas al aventajado pintor, nuestro amigo, Sr. D. Manuel Castellano, y hemos recibido de él una colección de fotografías, que consta no menos que de 24.000 artículos, retratos, paisajes, vistas de edificios, etc., en la cual entran, con muchos retratos desconocidos, casi todas las notabilidades de España"75. Aparte de no mencionar ninguna vez a José Martínez Sánchez como creador de estos álbumes, dicho documento cortó las especulaciones según las cuales las fotografías habrían llega-

Retrato Juan Eugenio de Hartzenbusch; Ibídem, Tomo 9, 17LF/54-10.3, Retrato Juan Eugenio de Hartzenbusch.

${ }^{72}$ J. M. SÁNCHEZ VIGIL (coord.), Op. cit., p.188 (nota 19). Aunque sea verdad que en su artículo publicado en 1992, Elena Páez ya mencionaba dicho documento, lo atribuía a Isidoro Rosel. E. PÁEZ, “Historia y organización de la sección de estampas de la Biblioteca Nacional", en Estampas: cinco siglos de imagen impresa. Catálogo de exposición, Madrid, 1992, pp.143-144.

${ }^{73}$ Juan Eugenio Hartzenbusch era escritor, crítico, pero sobre todo dramaturgo. Es probable que los dos hombres se hayan conocido dentro del ámbito teatral. De hecho, tenían suficiente confianza para intercambiar sus proyectos teatrales (BNE, MSS/12961/73, Carta de Juan Eugenio de Hartzenbusch a Manuel Castellano, 1861) y resulta muy poco probable que ignorase la colección de Castellano aún en esta época.

${ }^{74}$ Tres álbumes de la Colección Hartzenbusch se han conservado: BNE, Álbum de retratos pertenecientes a la familia Hartzenbusch I, 17-LF/63, ca.1858-1880; Ibídem, II, 17LF/64, ca.1860-1875 e Ibídem, III, 17-LF/65, ca.1860-1875.

${ }^{75}$ J. E. HARTZENBUSCH, Op. cit., p.9. “A esta colección ha acompañado otra del propio colector, no menos preciosa, compuesta de doscientas y una obras dramáticas manuscritas, casi todas autógrafas, de escritores modernos: los Sres. Bretón, García Gutiérrez, Ayala, Serra, Diana, Cazurro, Larra, Eguílaz, Sólgas, Camprodon, Retes, Hurtado, Gutiérrez de Alba, Núñez de Arce, Blasco, Puente y Brañas, Pedrosa, Gaspar, Nocedal (D. Kamon), etc., etc." 
do a los fondos de la Biblioteca solamente a la muerte del pintor. Además informa sobre una importante novedad introducida por Hartzenbusch. A su llegada como director, entendió inmediatamente que las donaciones de fotografías serían muy poco frecuentes ${ }^{76}$, o que incluso la institución era reticente a la compra de fondos por el coste que implicaba. Ideó por lo tanto una nueva estrategia de intercambios de fondos menores o duplicados de la biblioteca, para adquirir material fotográfico. En el caso del conjunto que nos interesa, utilizó una colección de estampas de Valentín Carderera que la biblioteca poseía en varios ejemplares ${ }^{77}$. El esfuerzo común por parte de los dos hombres permitió propulsar un medio fotográfico todavía escaso de popularidad al rango de objeto digno de ser representado en la institución. La segunda transacción, estimada en julio de $1880^{78}$-tan solo tres meses después de la muerte del pintor- parece contar de unas 800 fotografías ${ }^{79}$. Es más, la donación también incluía una cantidad excepcional de documentación -graba-

\footnotetext{
${ }^{76} \mathrm{Ibídem}$. Juan Eugenio Hartzenbusch explica que en 1871 ya había tenido la idea de pedir que se entregase a la BNE, por cada exposición de fotografía pública, un duplicado de las obras presentadas. Irónicamente, explica que los fotógrafos no lo respetaron: “Manifesté años ya la conveniencia de que se nos cediese gratis un ejemplar de cada fotografía que se expusiese á pública venta; los editores de esta clase de estampas, que hacen á cada paso regalos de cuanto dan á luz, olvidan, ó no han aprendido, el camino de nuestra Casa".

${ }^{77}$ Ibídem. "Con un gran número de estampas duplicadas y multiplicadas, que posee la Biblioteca, y pertenecieron á la copiosísima colección de grabados que el Gobierno compró al Sr. D. Valentín Carderera, hemos hecho un cambio, útil al Establecimiento".

${ }^{78}$ G. KURTZ e I. ORTEGA, 150 años de fotografía en la Biblioteca Nacional. Guía - inventario de los fondos fotográficos, Madrid, 1989, p.186.

${ }^{79}$ En 1992 recordaba esta transacción Luis García Ejarque, anunciando hasta el precio de venta de 6.500 pesetas, y Elena Páez añade que fue el mismo sobrino del pintor el que se encargó de la enajenación. Pero ninguna de estas teorías fue apoyada con documentos. Ver L. GARCÍA EJARQUE, "Biblioteca Nacional de España", Boletín de la Asociaciones de Archiveros, Bibliotecarios, Museólogos y Documentalistas, t. 42, nº 3-4, 1992, p. 217 y E. PÁEZ, Op. cit., p. 144.
}

dos, cartas, o periódicos varios de la época ${ }^{80}$ presentes en la colección.

Desgraciadamente, las intenciones de Castellano y Hartzenbusch no eran compartidas por todos. En la década de los ochenta del siglo XIX, la fotografía ya se había implantado en Madrid, pero no tanto en sus instituciones culturales. Todavía en la víspera del siglo XX el director de la sección de Bellas Artes de la Biblioteca Nacional Ángel Barcia, tenía dificultades para entender la inclusión de retratos anónimos en el fondo artístico de la institución. Basta consultar para demostrarlo, el Catálogo de los retratos de personajes españoles que se conservan en la sección de estampas y de Bellas Artes de la Biblioteca Nacional $^{81}$ que redactó en 1901. En dicho registro de autores, no cita a Manuel Castellano cuando sí recuerda en cambio a su hermano Ramón que era actor. En cuanto a la colección, solamente ocupa un apéndice al final del libro, en el que además parece disculparse por la inclusión de tal fondo en la publicación: "Repugnaba intercalar en el cuerpo del catálogo tales retratos faltos de todo valor artístico y aun muchos de ellos de todo interés histórico, por ser de personas oscuras y sólo conocidas de los que las trataron, pero por otra parte no convenía dejar de hacer mención de ellos puesto que al fin son retratos españoles y están en la biblioteca"82. La incorporación de obra fotográfica en la Biblioteca Nacional fue una tarea complicada y seguramente Juan Eugenio de Hartzenbusch y Manuel Castellano tuvieron que enfrentarse tanto a dificultades ideológicas como económicas para lograrlo. No obstante, su persistencia les permitió la conservación de un patrimonio imprescindible hoy en

${ }^{80}$ L. GARCÍA EJARQUE, Op.cit., p. 216. El autor describe la colección como compuesta de "248 láminas y 800 números de periódicos raros de varias épocas".

${ }^{81} \mathrm{~A}$. BARCIA, Catálogo de los retratos de personajes españoles que se conservan en la sección de estampas y de Bellas Artes de la Biblioteca Nacional, Madrid, 1901.

${ }^{82}$ Ibídem, p. 760. 
día para entender la sociedad madrileña del siglo XIX.

\section{CONCLUSIONES}

Frente a las diferentes teorías propuestas entorno a las condiciones de creación de la Colección Castellano, creemos imprescindible revalorizar y resaltar la figura de Manuel Castellano como personaje más que activo en la reunión - ¿y creación?- del fondo.

A nuestro juicio, el pintor se posicionó en aquel entonces como un ideólogo de la fotografía del siglo XIX, y permitió, junto a su círculo social, dinamizar y desarrollar un nuevo lenguaje expresivo en Madrid. Su propia ubicación en el seno del mundo teatral y su posición en la sociedad artística madrileña le coloca como un personaje clave a la hora de enlazar la fotografía con los diferentes ámbitos culturales de la capital. Sin embargo, y a pesar de haber manteni- do amistades con los principales fotógrafos madrileños, todavía no tenemos constancia de que Manuel Castellano haya sido autor de alguno de los retratos de la colección. Es más, a la luz de sus propias imágenes, resulta obvia la modernidad que presentan estos mismos. Indudablemente, el pintor estaba al tanto de las novedades fotográficas españolas y europeas, participando de alguna manera en el desarrollo de nuevas formas fotográficas en Madrid, además de cuidar de su conservación. Asimismo, la preponderancia de imágenes de José Martínez Sánchez en los tomos de muestra que la relación entre los dos hombres es digna de un interés particular, y esperamos por lo tanto haber abierto un foco de atención para futuras investigaciones. Quizá sería interesante seguir la pista de una colaboración entre Manuel Castellano y el núcleo de fotógrafos con el que se relacionaba, para entender plenamente uno de los fondos fotográfico más ricos de España. 